\title{
Identifikasi "Acne Vulgaris" berdasarkan Fitur Warna dan Tekstur Menggunakan Klasifikasi JST Backpropagation
}

\author{
Malia Elisiana', Ulla Delfana Rosiani' ${ }^{2}$, Kadek Suarjuna Batubulan ${ }^{3}$ \\ ${ }^{1,2}$ Teknik Informatika, Teknologi Informasi, ${ }^{3}$ Politeknik Negeri Malang \\ ${ }^{1}$ Maliaelsi5@gmail.com, ${ }^{2}$ Rosiani@ polinema.ac.id, ${ }^{3}$ Kadeksuarjuna87@gmail.com
}

\begin{abstract}
Abstrak
Acne Vulgaris adalah salah satu penyakit kulit kronis umum yang berkaitan dengan penyumbatan dan atau peradangan pada folikel rambut dan kelenjar minyak yang menyertainya. Acne vulgaris dibagi menjadi beberapa macam jenis, diantaranya ada whitehead, blackhead, papule, dan pustule. Beberapa jenis acne vulgaris memiliki warna dan tekstur yang berbeda. Hasil dari ekstraksi warna dan tekstur dapat dilakukan klasifikasi terhadap jenis acne vulgaris. Dengan berkembangnya teknologi bidang informatics engineering proses identifikasi jenis acne vulgaris dapat dilakukan menggunakan pengolahan citra digital. Hasil dari ekstraksi fitur warna dan fitur tekstur kemudian dianalisis dan diklasifikasikan sehingga dapat diketahui jenis acne vulgaris pada citra tersebut. HSV merupakan salah satu ruang warna yang memperlihatkan warna seperti yang dilihat oleh manusia pada umumnya. GLCM merupakan metode yang mampu menyediakan informasi penting dan melakukan analisis mengenai tekstur citra. Empat ciri statistik GLCM yaitu contrast, correlations, homogenity, dan energy dengan sudut $0^{\circ}, 45^{\circ}, 90^{\circ}$, dan $135^{\circ}$ akan memberikan nilai untuk membedakan tekstur acne vulgaris pada setiap jenisnya. Backpropagation digunakan karena metode tersebut mampu menyelesaikan pengklasifikasian dengan problem nonlinear. Terdapat tiga tahap backpropagation dalam pengolahan data yaitu tahap feedfordward, backpropagation, dan penyesuaian bobot, sedangkan untuk klasifikasi menggunakan tahap feedfordward. Dari hasil penelitian mengidentifikasi acne vulgaris menggunakan ruang warna HSV, metode GLCM dan klasifikasi JST Backpropagation dapat menghasilkan nilai akurasi sebesar 65\%. Akurasi tersebut didapatkan dari parameter learning rate 0.0002 dan epoch sebanyak 200.
\end{abstract}

Kata kunci : acne vulgaris, pengolahan citra, HSV, GLCM, backpropagation

\section{Pendahuluan}

Acne Vulgaris adalah salah satu penyakit kulit kronis umum yang berkaitan dengan penyumbatan dan atau peradangan pada folikel rambut dan kelenjar minyak yang menyertainya. Acne Vulgaris ditandai dengan beberapa macam lesi, seperti lesi komedo dan lesi inflamasi (Dawson \& Dellavalle, 2013) Lesi komedo terdiri dari whitehead dan blackhead, sedangkan lesi inflamasi terdiri dari papule dan pustule.Whitehead muncul sebagai benjolan kecil berwarma putih daging di permukaan kulit, merupakan bentuk dimana pori-pori tersumbat dibagian bawah kulit. Blackhead terjadi ketika bagian atas whitehead terkena udara yang menyebabkan sebum teroksidasi dari putih menjadi hitam. Sedangkan papule dan pustule merupakan jenis yang meradang. Papule terjadi ketika whitehead terinfeksi oleh bakteri, ditandai dengan muncul benjolan kecil berwarna merah meradang. Jika papule terkena iritasi, maka banyak kemungkinan papule tersebut berubah menjadi pustule, dimana benjolan yang meradang tersebut terdapat nanah yang mengisi di bagian tengahnya.

Dalam penanganan acne vulgaris, hal yang pertama kali harus dilakukan adalah mengidentifikasi jenisnya sehingga dapat dilakukan penanganan yang tepat, baik penanganan yang mudah ditangani maupun penanganan yang sulit ditangani. Beberapa jenis acne vulgaris memiliki warna dan tekstur yang berbeda. Hasil dari identifikasi warna dan tekstur tersebut dapat dilakukan klasifikasi terhadap jenis acne vulgaris. Dengan berkembangnya teknologi dalam bidang informatics engineering proses identifikasi jenis acne vulgaris dapat dilakukan menggunakan pengolahan citra digital. Dengan pengolahan citra digital sebuah citra acne vulgaris dapat diidentifikasi dengan ekstraksi fitur warna dan fitur tekstur. Hasil dari ekstraksi fitur warna dan fitur tekstur kemudian dianalisis dan diklasifikasikan sehingga dapat diketahui jenis acne vulgaris pada citra tersebut.

HSV merupakan salah satu ruang warna yang memperlihatkan warna seperti yang dilihat oleh manusia pada umumnya. Acne vulgaris merupakan citra yang dapat dilihat oleh manusia dengan berdasarkan warnanya. GLCM merupakan metode yang mampu menyediakan informasi penting dan melakukan analisis mengenai tekstur citra. Empat ciri statistic GLCM yaitu contrast, correlations, homogenity, dan energy dengan sudut $0^{\circ}, 45^{\circ}, 90^{\circ}$, dan $135^{\circ}$ akan memberikan nilai untuk membedakan tekstur acne vulgaris pada setiap jenisnya. JST 
Backpropagation adalah metode untuk pengenalan pola, pembentukan pola, dan klasifikasi pola. Backpropagation digunakan karena metode tersebut mampu menyelesaikan pengklasifikasian dengan problem non-linear. Dengan pemaparan tersebut, penulis membuat penelitian untuk mengidentifikasi acne vulgaris menggunakan ruang warna $\mathrm{HSV}$, metode GLCM dan klasifikasi JST Backpropagation yang diharapkan dari penelitian ini dapat menghasilkan nilai akurasi yang lebih baik.

\section{Metodologi Peneitian}

Dalam sebuah penelitian agar proses mengembangkan perangkat lunak lebih cepat, tepat dan terstruktur, maka diperlukan sebuah metodologi khusus. Metode pengembangan perangkat lunak merupakan suatu proses dimana terdapat sekumpulan tahapan-tahapan tertentu untuk mengembangkan perangkat lunak. Umunya diperlukan metodologi agar menghasilkan perangkat lunak yang lebih baik dan berkualitas.

Dalam penelitian ini, digunakan metode waterfall untuk pengembangan perangkat lunak. Metode waterfall merupakan metode umum yang seringkali digunakan dalam penelitian. Metode waterfall bersifat sistematis dan tersusun secara berurutan. Tahapan-tahapan dalam metode ini yang pertama yaitu dengan menganalisa kebutuhan, kemudian dilanjutkan dengan mendesain sistem, implementasi, mengintegrasi dan melakukan pengujian dan yang terakhir melakukan pemeliharaan. Desain dari metode waterfall yang digunakan pada sistem dapat digambarkan sebagai berikut:

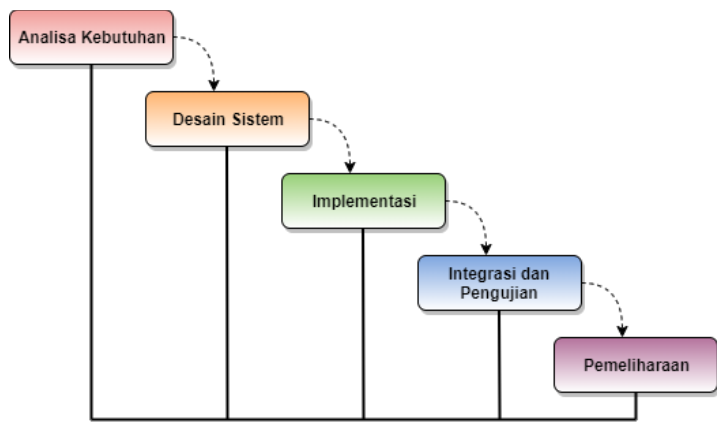

Gambar 1. Metode Waterfall

\subsection{Sumber Data}

Metode pengambilan data gambar yang digunakan diambil secara online, salah satunya pada situs dermnetnz.org, derment.com dan skinsight.com., dermnetnz.org adalah sebuah situs dengan sumber informasi yang terkenal didunia mengenai kulit dan telah disertifikasi Health-on-Thenet (HON). Derment.com adalah sumber foto dermatologi yang terbesar yang memberikan informasi tentang berbagai kondisi kulit. Skinsight.com merupakan situs yang didekasikan untuk memberikan informasi kesehatan yang berkualitas mengenai kulit.

\subsection{Analisis Sistem}

Analisis sistem merupakan suatu penguraian mengenai komponen-komponen yang mendefinisikan kebutuhan sistem yang sedang dirancang pada penelitian ini baik mengenai kebutuhan fisik maupun non-fisik. Analisa dilakukan pada perangkat lunak, perangkat keras dan gambaran umum sistem atau aplikasi.

Aplikasi identifikasi "acne vulgaris" berdasarkan fitur warna dan tekstur dengan menggunakan klasifikasi JST Backpropagation ini menggunakan bahasa pemrograman $\mathrm{C} \#$ dan dirancang menggunakan Visual Studio 2017. Citra acne vulgaris yang digunakan sebagai objek penelitian adalah whitehead, blackhead, papule, dan pustule. Secara umum, sistem aplikasi ini memiliki beberapa proses yaitu proses esktraksi fitur warna menggunakan HSV, proses ekstraksi fitur tekstur menggunakan GLCM, proses training, dan proses testing menggunakan klasifikasi JST Backpropagation. Dalam JST backpropagation terdapat tiga lapisan yang digunakan. Berikut pada Tabel 1. merupakan tabel penjabaran nilai dari tiaptiap layer:

Tabel 1. Penjabaran 3 lapisan JST Backpropagation

\begin{tabular}{|c|c|c|}
\hline $\begin{array}{c}\text { Jenis } \\
\text { Layer }\end{array}$ & Keterangan & Nilai \\
\hline $\begin{array}{l}\text { Input } \\
\text { Layer }\end{array}$ & $\begin{array}{ll}\text { 1. } & \text { Hue } \\
\text { 2. } & \text { Saturation } \\
\text { 3. } & \text { Value } \\
\text { 4. } & \text { Contrast } \\
\text { 5. } & \text { Energy } \\
\text { 6. } & \text { Homogenity } \\
\text { 7. } & \text { Correlations }\end{array}$ & 7 \\
\hline $\begin{array}{l}\text { Hidden } \\
\text { Layer }\end{array}$ & 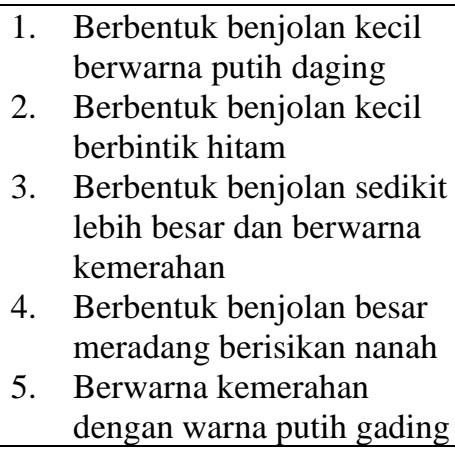 & 5 \\
\hline $\begin{array}{l}\text { Output } \\
\text { Layer }\end{array}$ & $\begin{array}{ll}\text { 1. } & \text { Whitehead } \\
\text { 2. } & \text { Blackhead } \\
\text { 3. } & \text { Papule } \\
\text { 4. } & \text { Pustule }\end{array}$ & 4 \\
\hline
\end{tabular}

\subsection{Perancangan Sistem}

Perancangan sistem merupakan suatu proses merancang atau mendesain sebuah sistem yang isinya terdapat langkah-langkah pengoperasian dan 
pengolahan data pada aplikasi. Rancangan sistem ini berupa desain dalam bentuk diagram flowchart.

a. Diagram Alur Sistem

Alur sistem pada aplikasi dibagi menjadi dua tahapan yaitu tahap training dan tahap testing. Kedua tahap tersebut digambarkan dalam bentuk diagram flowchart.

\section{Proses Training}

Proses training dilakukan untuk mencari nilai ciri dari citra masukan yang akan disimpan kedalam database sebagai tolak ukur data uji. Pada Gambar 3. berikut merupakan tampilan flowchart dari proses training:

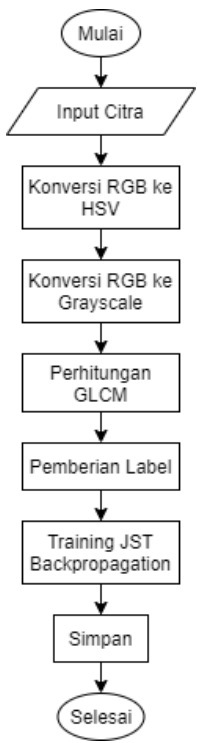

Gambar 2. Diagram flowchart training data

\section{Proses Testing}

Proses testing dilakukan untuk mencari nilai ciri dari citra masukan yang kemudian diujikan dengan proses klasifikasi dengan metode JST Backpropagation. Pada Gambar 4. berikut merupakan tampilan flowchart dari proses testing:

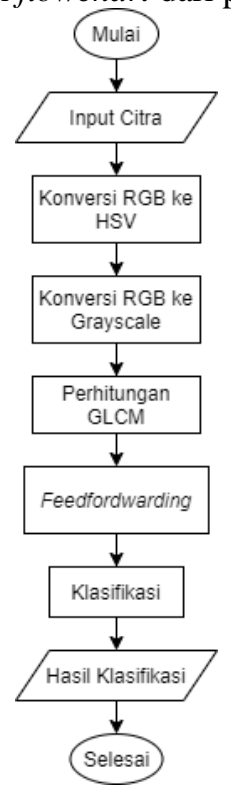

Gambar 3. Diagram flowchart testing data

\section{Hasil Dan Pembahasan}

\subsection{Pengujian}

Pengujian dilakukan untuk mengetahui kesesuaian aplikasi "Identifikasi Acne Vulgaris Berdasarkan Fitur Warna dan Tekstur Menggunakan Klasifikasi JST Backpropagation" dengan tujuan pembuatan sistem dalam penelitian. Metode pengujian sistem terbagi menjadi dua macam yaitu pengujian sistem dan pengujian akurasi.

\section{Pengujian Sistem}

Pengujian sistem bertujuan untuk memastikan bahwa setiap fungsi pada aplikasi sesuai dengan yang diperlukan dan berjalan dengan benar. Pengujian ini dilakukan menggunakan metode blackbox. Pengujian blackbox digunakan untuk menemukan kesalahan aplikasi yang sedang diuji, guna mengetahui apakah seluruh fungsi dapat berjalan dengan baik.

Berikut ini merupakan tampilan dari proses ekstraksi fitur warna dan tesktur pada form utama aplikasi:

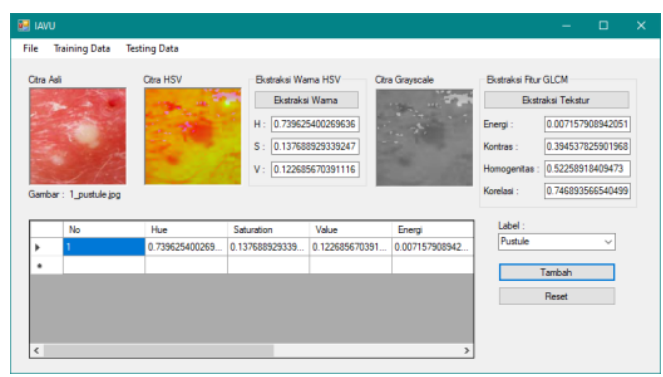

Gambar 4. Proses ekstraksi fitur

Setelah dilakukan proses ekstraksi fitur pada form utama, maka akan dilakukan training data pada form training yaitu dengan menginputkan parameter, dan dataset hasil ekstraksi, kemudian akan di training hingga menghasilkan bobot terbaik. Berikut ini merupakan tampilan dari proses training backpropagation :

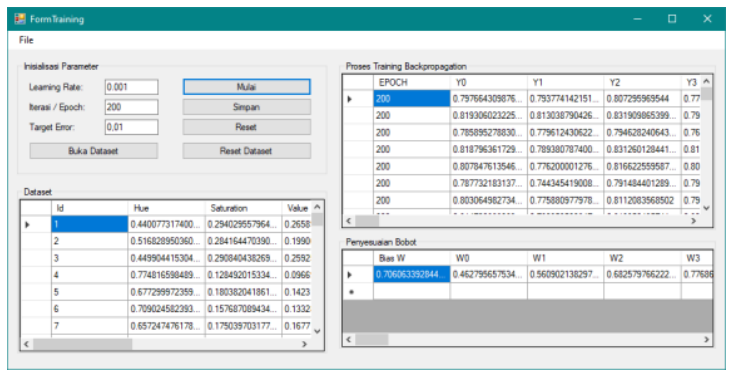

Gambar 5. Proses training backpropagation

Pada form testing dilakukan tahap-tahap seperti pada form utama. Dengan menggunakan bobot terbaik yang dihasilkan pada proses training akan mendapatkan hasil klasifikasi seperti pada Gambar 13 dibawah ini: 


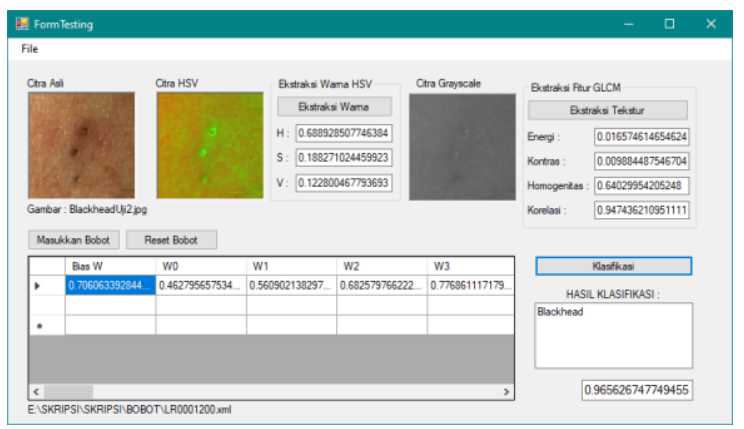

Gambar 6. Proses klasifikasi

\section{Pengujian Akurasi}

Pengujian akurasi bertujuan untuk mengetahui tingkat keberhasilan dari sistem dalam mengenali jenis acne vulgaris. Pengujian dilakukan dengan menggunakan learning rate 0.0002 dan epoch 200 dengan keterangan sebagai berikut:

Tabel 2. Pengujian dengan learning rate 0.0002 dan epoch 200

\begin{tabular}{|c|c|c|c|c|}
\hline $\begin{array}{c}\text { Citra } \\
\text { Acne } \\
\text { Vulgaris }\end{array}$ & $\begin{array}{c}\text { Identifika } \\
\text { si Visual }\end{array}$ & $\begin{array}{c}\text { Identifika } \\
\text { si Sistem }\end{array}$ & $\begin{array}{c}\text { Ketera } \\
\text { ngan }\end{array}$ & Nilai Output \\
\hline Citra W1 & Whitehead & Whitehead & Benar & 0.893766655299332 \\
\hline Citra W2 & Whitehead & Whitehead & Benar & 0.895792966502924 \\
\hline Citra W3 & Whitehead & Whitehead & Benar & 0.894834688629813 \\
\hline Citra W4 & Whitehead & Pustule & Salah & 0.898768707334092 \\
\hline Citra W5 & Whitehead & Whitehead & Benar & 0.888480019865586 \\
\hline Citra B1 & Blackhead & Whitehead & Salah & 0.892011214280768 \\
\hline Citra B2 & Blackhead & Blackhead & Benar & 0.897702421101337 \\
\hline Citra B3 & Blackhead & Whitehead & Salah & 0.880797709832288 \\
\hline Citra B4 & Blackhead & Blackhead & Benar & 0.896040735865308 \\
\hline Citra B5 & Blackhead & Blackhead & Benar & 0.896326239200211 \\
\hline $\begin{array}{c}\text { Citra } \\
\text { PA1 }\end{array}$ & Papule & Papule & Benar & 0.912168898899606 \\
\hline $\begin{array}{c}\text { Citra } \\
\text { PA2 }\end{array}$ & Papule & Papule & Benar & 0.904331064226926 \\
\hline $\begin{array}{l}\text { Citra } \\
\text { PA3 }\end{array}$ & Papule & Papule & Benar & 0.90649761026521 \\
\hline $\begin{array}{c}\text { Citra } \\
\text { PA4 }\end{array}$ & Papule & Papule & Benar & 0.904290253335249 \\
\hline $\begin{array}{l}\text { Citra } \\
\text { PA5 }\end{array}$ & Papule & Whitehead & Salah & 0.893913912504276 \\
\hline $\begin{array}{l}\text { Citra } \\
\text { PU1 }\end{array}$ & Pustule & Pustule & Benar & 0.901028978705745 \\
\hline $\begin{array}{l}\text { Citra } \\
\text { PU2 }\end{array}$ & Pustule & Whitehead & Salah & 0.893368122140182 \\
\hline $\begin{array}{l}\text { Citra } \\
\text { PU3 }\end{array}$ & Pustule & Whitehead & Salah & 0.894184676283257 \\
\hline $\begin{array}{l}\text { Citra } \\
\text { PU4 }\end{array}$ & Pustule & Whitehead & Salah & 0.894975631893565 \\
\hline $\begin{array}{l}\text { Citra } \\
\text { PU5 }\end{array}$ & Pustule & Pustule & Benar & 0.901714275035051 \\
\hline
\end{tabular}

Untuk mengetahui tingkat akurasi dari sistem dapat dihitung menggunakan rumus sebagai berikut:

Akurasi $=\frac{\text { Jumlah Citra Benar }}{\text { Jumlah } \text { Total Citra }} \times 100 \%$

Dalam pengujian akurasi dilakukan dengan beberapa sampel citra acne vulgaris dengan rincian seperti pada Tabel 3. berikut:

Tabel 3. Rekap pengujian error sistem

\begin{tabular}{|c|c|c|c|c|}
\hline $\begin{array}{c}\text { Jenis } \\
\text { Acne } \\
\text { Vulgaris }\end{array}$ & $\begin{array}{c}\text { Jumlah } \\
\text { Sampel }\end{array}$ & Sesuai & $\begin{array}{c}\text { Tidak } \\
\text { Sesuai }\end{array}$ & Error \\
\hline Whitehead & 5 & 4 & 1 & $20 \%$ \\
\hline
\end{tabular}

\begin{tabular}{|l|c|c|c|c|}
\hline Blackhead & 5 & 3 & 2 & $40 \%$ \\
\hline Papule & 5 & 4 & 1 & $20 \%$ \\
\hline Pustule & 5 & 2 & 3 & $60 \%$ \\
\hline Total & 20 & 13 & 7 & $35 \%$ \\
\hline
\end{tabular}

Pada rekap pengujian diatas menunjukkan jumlah citra acne vulgaris yang digunakan adalah 20 sampel. Untuk mengetahui tingkat akurasi dari sistem dapat dihitung menggunakan rumus sebagai berikut: Akurasi $=\frac{13}{20} \times 100 \%=65 \%$

\subsection{Pembahasan}

Pada pengujian akurasi didapatkan nilai akurasi sebesar $65 \%$ dan tingkat error $35 \%$ dengan menggunakan parameter learning rate 0.0002 dan epoch 200. Data sampel yang untuk pengujian adalah 20 sampel, dengan masing-masing label citra sejumlah 5 sampel. Berikut merupakan gambaran grafik distribusi pada masing-masing label pada tiap fitur.

Dapat diketahui pada pola grafik distribusi pada fitur hue menunjukkan bahwa setiap jenis label mengalami penurunan frekuensi pada hue 0.7. Blackhead memiliki frekuensi terendah di hue 0.6 dan Pustule memiliki frekuensi tertinggi di hue 0.65. Sedangkan Whitehead dan papule berada diantara frekuensi hue blackhead dan pustule. Berikut merupakan gambar grafik distribusi hue:

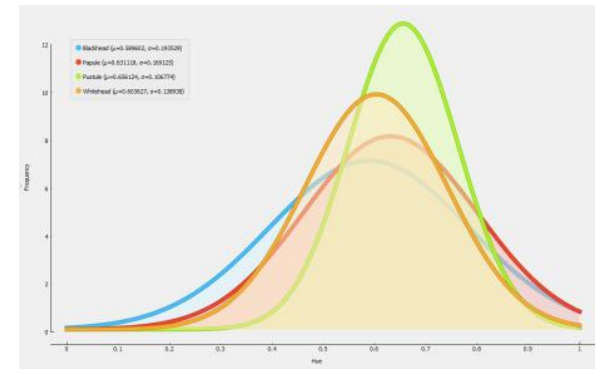

Gambar 7. Grafik distribusi hue

Dapat diketahui pada pola grafik distribusi pada fitur saturation menunjukkan bahwa setiap jenis label mengalami penurunan frekuensi pada saturation 0.3 . Blackhead memiliki frekuensi terendah di saturation 0.24 dan Pustule memiliki frekuensi tertinggi di saturation 0.18. Sedangkan Whitehead dan papule berada diantara frekuensi saturation blackhead dan pustule. Berikut merupakan gambar grafik distribusi saturation:

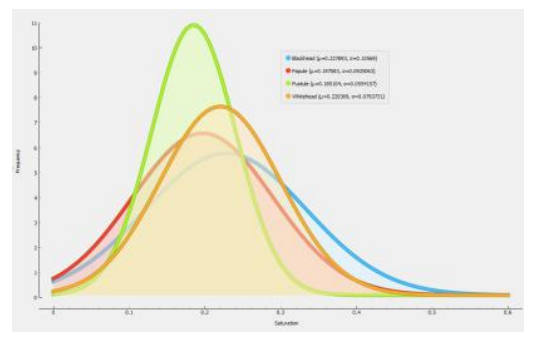

Gambar 8. Grafik distribusi saturation 
Sama halnya seperti pada grafik distribusi fitur hue dan saturation, menunjukkan bahwa setiap jenis label mengalami penurunan frekuensi pada value 0.2. Blackhead memiliki frekuensi terendah di value 0.18 dan Pustule memiliki frekuensi tertinggi di value 0.16. Sedangkan Whitehead dan papule berada diantara frekuensi value blackhead dan pustule. Berikut merupakan gambar grafik distribusi value :

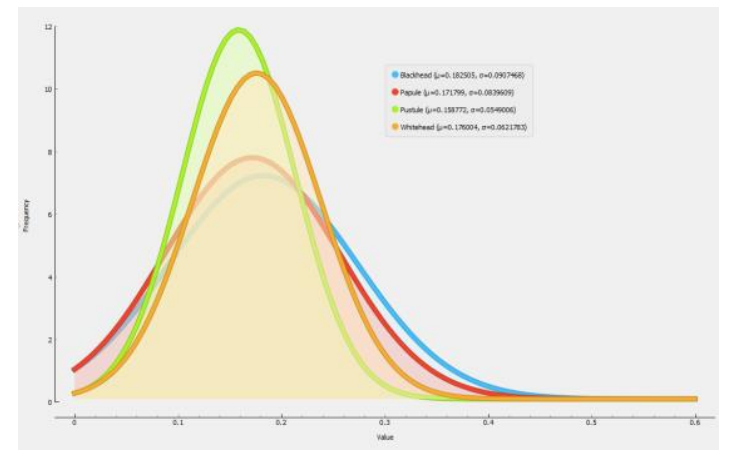

Gambar 9. Grafik distribusi value

Dapat diketahui pada pola grafik distribusi pada fitur energy menunjukkan bahwa pustule memiliki frekuensi tertinggi dengan nilai 0.01. Dan whitehead memiliki frekuensi terendah dengan nilai 0.03. Sedangkan blackhead dan papule berada diantara frekuensi energy whitehead dan pustule. Berikut merupakan gambar grafik distribusi energy:

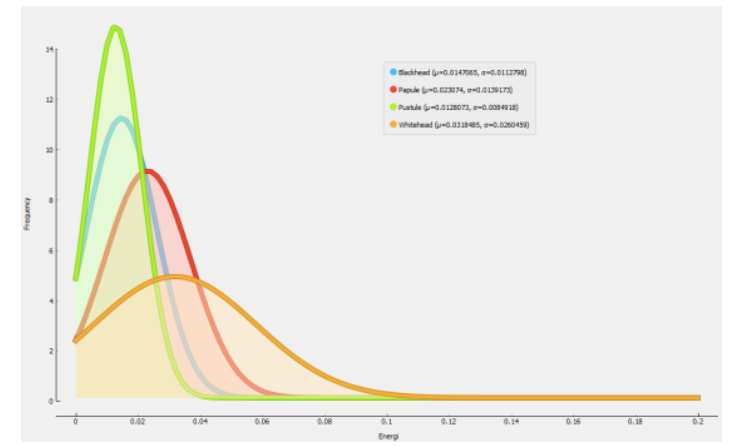

Gambar 10. Grafik distribusi energy

Dapat diketahui pada pola grafik distribusi pada fitur contrast menunjukkan bahwa whitehead memiliki frekuensi tertinggi dengan nilai 0.01 . Sedangkan untuk label yang lain tidak menunjukkan adanya kenaikan frekuensi yang signifikan. Berikut merupakan gambar grafik distribusi contrast :

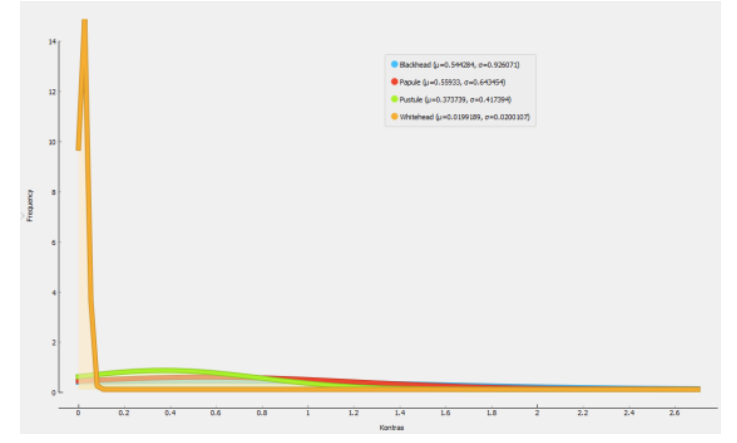

\section{Gambar 11. Grafik distribusi contrast}

Dapat diketahui pada pola grafik distribusi pada fitur homogeneity menunjukkan bahwa whitehead memiliki frekuensi tertinggi dengan nilai 0.62. Dan blackhead memiliki frekuensi terendah dengan nilai 0.5. Sedangkan papule dan pustule berada diantara frekuensi homogeneity blackhead dan whitehead. Berikut merupakan gambar grafik distribusi homogenity:

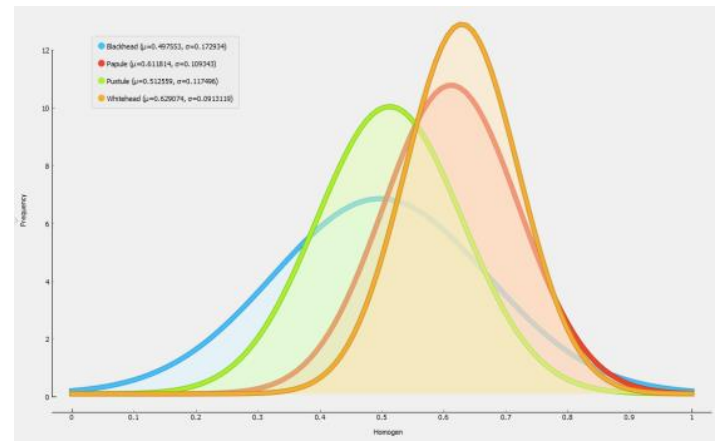

Gambar 12. Grafik distribusi homogeneity

Dapat diketahui pada pola grafik distribusi pada fitur hue menunjukkan bahwa whitehead memiliki frekuensi tertinggi di correlation sebesar 0.82 dan blackhead memiliki frekuensi terendah di correlation dengan nilai 0.65 . Sedangkan papule dan pustule berada diantara frekuensi correlation blackhead dan whitehead. Berikut merupakan gambar grafik distribusi correlation :

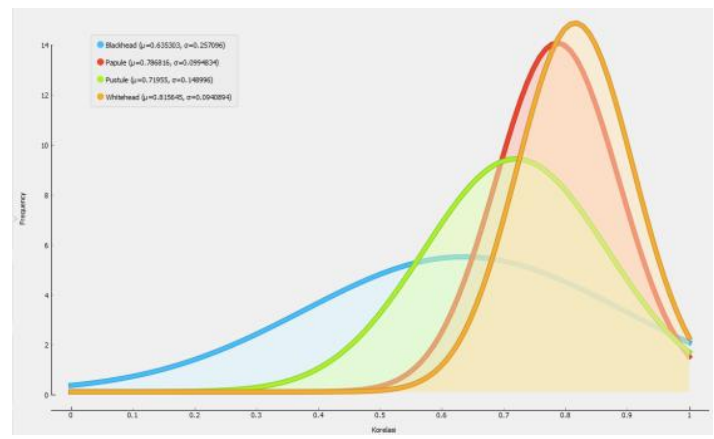

Gambar 13. Grafik distribusi correlation

Rentang nilai yang hampir sama pada tiap label menandakan bahwa fitur yang digunakan tidak dapat membuat label menjadi unik yang artinya fitur tersebut kurang cocok untuk digunakan pada identifikasi acne vulgaris ini.

\section{Kesimpulan}

Berdasarkan penelitian yang telah dilakukan, Tingkat akurasi yang didapatkan pada aplikasi "Identifikasi Acne Vulgaris Berdasarkan Fitur Warna Dan Tekstur Menggunakan Klasifikasi JST Backpropagation" sebesar $65 \%$ dengan menggunakan learning rate 0.0002 dan epoch 200 . Besarnya akurasi dipengaruhi oleh banyaknya data yang digunakan dan perbedaan jenis acne vulgaris satu dengan yang lain. Kemudian Rendahnya akurasi 
menandakan bahwa fitur yang digunakan tidak dapat membuat label menjadi unik.

Dari penelitian yang telah dilakukan penulis berharap untuk kedepannya, penelitian ini dapat dikembangkan dalam versi mobile sehingga dapat mempermudah dalam penggunaan aplikasi. Dengan dibuatnya penelitian ini semoga dapat dijadikan referensi untuk penelitian lebih lanjut seperti menggunakan fitur dan metode yang berbeda.

\section{Daftar Pustaka:}

Asmara, R. A., Puspitasari, D., Romlah, S., Hasanah, Q., \& Romario, R. (2017). IDENTIFIKASI KESEGARAN DAGING SAPI BERDASARKAN CITRANYA DENGAN EKSTRAKSI FITUR WARNA DAN TEKSTURNYA MENGGUNAKAN METODE GRAY LEVEL COOCCURRENCE MATRIX. SENTIA 2017, 9(0), Article 0. https://prosiding.polinema.ac.id/sentia/index. php/SENTIA2017/article/view/236

Astiningrum, M., Arhandi, P. P., \& Ariditya, N. A. (2019). Identifikasi Penyakit pada Daun Tomat Berdasarkan Fitur Warna dan Tekstur. Seminar Informatika Aplikatif Polinema, 227-230.

Bisri, H., Bustomi, M. A., \& Purwanti, E. (2013). Klasifikasi Citra Paru-Paru dengan Ekstraksi Fitur Histogram dan Jaringan Syaraf Tiruan Backpropagation. Jurnal Sains dan Seni ITS, 2(2), B68-B71-B71. https://doi.org/10.12962/j23373520.v2i2.419 3

Dawson, A. L., \& Dellavalle, R. P. (2013). Acne vulgaris. Bmj, 346, f2634.

Fathurrahman, M. I., Jondri, J., \& Rohmawati, A. A. (2019). Sistem Klasifikasi Kualitas Kayu Jati Berdasarkan Jenis Tekstur Dengan Jaringan Syaraf Tiruan Menggunakan Gray-level-co-occurrence Matrix. eProceedings of Engineering, 6(2).

Haryati, D. F., Abdillah, G., \& Hadiana, A. I. (2016). KLASIFIKASI JENIS BATUBARA MENGGUNAKAN JARINGAN SYARAF TIRUAN DENGAN ALGORITMA BACKPROPAGATION. 6.

Kusumaningtyas, S., \& Asmara, R. A. (2016). IDENTIFIKASI KEMATANGAN BUAH TOMAT BERDASARKAN WARNA MENGGUNAKAN METODE JARINGAN SYARAF TIRUAN (JST). Jurnal Informatika Polinema, 2(2), 72-72. https://doi.org/10.33795/jip.v2i2.59

Mulia, M., Arum Sari, Y., \& Sutrisno, S. (2019). Klasifikasi Citra Jenis Makanan dengan Color Moments, Morphological Shape Descriptors, dan Gray Level Coocurrence Matrix menggunakan Neighbor Weight $K$ Nearest Neighbor. 3, 4210-4217.
Muzdalifah, N., \& Adi, K. (2016). Identifikasi Jenis Jerawat dengan Wavelet Haar dan Jaringan Syaraf Tiruan Propagasi Balik. Youngster Physics Journal, 5(4), 171-178.

Putra, D. (2010). Pengolahan citra digital. Penerbit Andi.

Putri, R. R. P., Furqon, M. T., \& Rahayudi, B. (2018). Implementasi Metode JST-Backpropagation Untuk Klasifikasi Rumah Layak Huni (Studi Kasus: Desa Kidal Kecamatan Tumpang Kabupaten Malang). Jurnal Pengembangan Teknologi Informasi dan Ilmu Komputer eISSN, 2548, 964X.

Ramadhani, M., Suprayogi, S., \& Dyah, H. B. (2018). Klasifikasi Jenis Jerawat Berdasarkan Tekstur Dengan Menggunakan Metode Glcm. eProceedings of Engineering, 5(1).

Rozi, I. F., Pramitarini, Y., \& Puspitasari, N. (2020). ANALISIS MENGENAI CALON PRESIDEN INDONESIA 2019 DI TWITTER MENGGUNAKAN METODE BACKPROPAGATION. Jurnal Informatika Polinema, 6(2), 27-31.

Sudibyo, U., Kusumaningrum, D. P., Rachmawanto, E. H., \& Sari, C. A. (2018). OPTIMASI ALGORITMA LEARNING VECTOR QUANTIZATION (LVQ) DALAM PENGKLASIFIKASIAN CITRA DAGING SAPI DAN DAGING BABI BERBASIS GLCM DAN HSV. Simetris: Jurnal Teknik Mesin, Elektro dan Ilmu Komputer, 9(1), 110. ttps://doi.org/10.24176/simet.v9i1.1943

Sulistiyasni. (2020). Klasifikasi Pola Sidik Jari Menggunakan Jaringan Syaraf Tiruan Backpropagation. BIMIPA. (t.t.). https://dev.jurnal.ugm.ac.id/bimipa/article/v iew/25956 